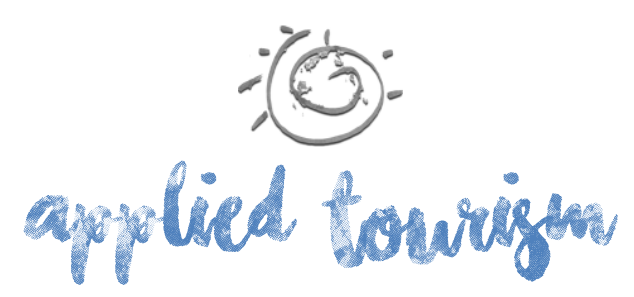

Volume 2, número 1,2017, p. 68-94

\title{
CRUZEIROS MARÍTIMOS: tendência da demanda no mercado brasileiro e internacional para os próximos 5 anos, a partir de 2016
}

\author{
Carlos Eduardo de Almeida Ramoa \\ Doutorando em Turismo e Hotelaria \\ Universidade do Vale do Itajaí \\ carlos.eduardo.ramoa@gmail.com
}

Luiz Carlos da Silva Flores

Professor do PPG em Turismo e Hotelaria

Universidade do Vale do Itajaí luiz.flores@univali.br

Recebido: 24 de junho, 2016

Aprovado: 14 de dezembro, 2016

\section{RESUMO}

Ao contrário do que vem ocorrendo no mercado internacional, o turismo marítimo no Brasil tem apresentado queda na taxa de crescimento desde 2011. Este artigo tem por objetivo verificar as perspectivas do mercado brasileiro e mundial por cruzeiros marítimos para os próximos cinco anos a partir de 2016. Para isso foi realizado um estudo de caráter exploratório e descritivo de forma a analisar históricos da oferta e demanda, de 2006 a 2015. Utilizou-se o método de procedimento estatístico e funções estatísticas de regressão para se obter a projeção da tendência futura. Os resultados apresentados indicam que, se fosse mantida a tendência verificada até 2010 , a perspectiva da demanda no Brasil seria de crescimento, como vem ocorrendo no mercado internacional.

Palavras-chave: Cruzeiros marítimos. Tendência da demanda de cruzeiristas. Regressão estatística. 


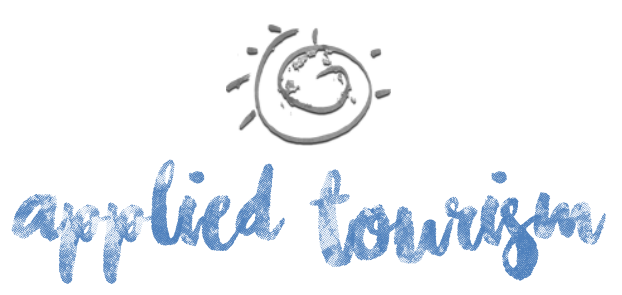

Volume 2, número 1,2017, p. 68-94

Assim sendo, verifica-se que a demanda por cruzeiros marítimos no Brasil apresentou crescimento exponencial de mais de 2000\% no período entre as temporadas 2000/2001 e 2009/2010 (CLIA-ABREMAR, 2010, p. 7). No entanto, nos anos seguintes houve uma redução nos números percentuais de cruzeiristas (CLIA-ABREMAR, 2011). A taxa de crescimento acima de 30\% ao ano é mantida até 2009/2010, porém a partir de 2010/2011 reduziu para 10\%, em relaçãoà temporada anterior. No período de 2011/2012 ocrescimento foi de 1,57\% em relação à 2010/2011 e em 2012/2013 o número percentual de cruzeiristas caiu 9\% em relação à 2011/2012, sinalizando que as águas, antes calmas, passaram a apresentar certa turbulência (CLIA ABREMAR BRASIL, 2016a).

Enquanto no Brasil o número de cruzeiristas vem caindo (CLIA-ABREMAR, 2016b), o mercado global, europeu e da América do Norte, vem mantendo taxas crescentes da demanda (CLIA, 2016). Este crescimento vinha justificando o aumento da oferta de navios no litoral brasileiro, que passou de seis na temporada 2004/2005 para vinte navios em 2010/2011 (CLIA-ABREMAR, 2016b). No entanto, de acordo com a Associação Brasileira de Cruzeiros Marítimos (CLIA ABREMAR, 2016b), em 2011/2012, o número caiu continuamente: dezessete em 2012/2013; quinze em 2012-2013, onze em 2013-2014; dez em 2014-2015 e 2015-2016, Confirmando a tendência de queda da demanda, apontada por Ramoa (2014) e Ramoa \& Flores (2015a), a previsão para a temporada 2016/2017 é de sete navios (CLIA-ABREMAR, 2016c). Estas reduções fazem com que surjam dúvidas em relação ao futuro do mercado de cruzeiros marítimos no Brasil.

Neste contexto, o objetivo geral desta pesquisa é de verificar as perspectivas do mercado brasileiro e internacional por cruzeiros marítimos para os próximos cinco anos, a partir de 2016. Para atender a este objetivo a metodologia da pesquisa inclui análise de regressão estatística feita a partir de técnicas de documentação indireta, pesquisa documental e revisão da literatura sobre esses mercados. 


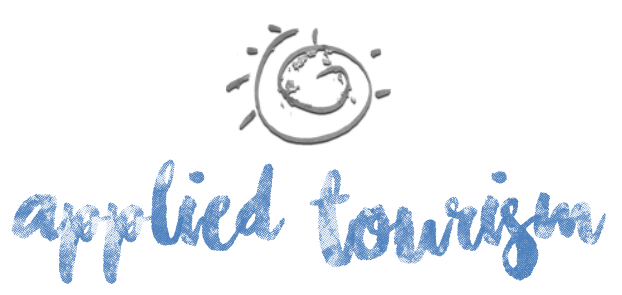

Volume 2, número 1,2017, p. 68-94

Os autores consideram a importância deste estudo para se conhecer, além da demanda passada, nos principais países do ranking internacional de cruzeiros marítimos, também a tendência para o futuro destes mercados.

\section{REFERENCIAL TEÓRICO}

\section{O turismo e o cruzeiro marítimo}

Um cruzeiro marítimo tem por característica a possibilidade de conhecer diversos destinos em um curto espaço de tempo, por um valor adequado à capacidade de pagamento, sem a necessidade de fazer e desfazer malas em cada escala, agregando experiências de lazer, gastronomia e entretenimento a bordo. Um navio de cruzeiro se assemelha a um resort móvel que transporta passageiros de um lugar para outro, deslocando-se atrás principalmente do calor e do sol, fazendo com que o clima seja um fator determinante no desenvolvimento do destino (Dowling, 2006).

No conceito do turismo marítimo, existe uma definição mais elementar para cruzeiro, que é simplesmente uma viagem de férias em um navio. Para o cruzeirista os objetivos principais são satisfazer o seu desejo de relaxar, ficar longe de tudo, ter uma nova experiência, aprender, ser mimado e se divertir (Mancini, 2010). Na busca da realização de sonhos, o cruzeiro é uma forma de consumo que reflete status e promete a realização imediata de um desejo (Vogel \& Oschmann, 2012).

O turismo em uma viagem de navio passou a ser uma nova opção de lazer desde a transformação dos transatlânticos de transporte de passageiros em navios de cruzeiro, após terem perdido mercado devido à popularização das companhias aéreas. Criou-se então um novo mercado onde não existia antes (WTO, 2010). Viajar em um navio não significa que o turista irá apenas realizar mais uma viagem, mas esta alternativa de férias lhe dará a oportunidade de usufruir de um conjunto de opções de lazer e entretenimento em pleno oceano em detrimento aos tradicionais destinos turísticos terrestres (Mendes \& Silva, 2012). 


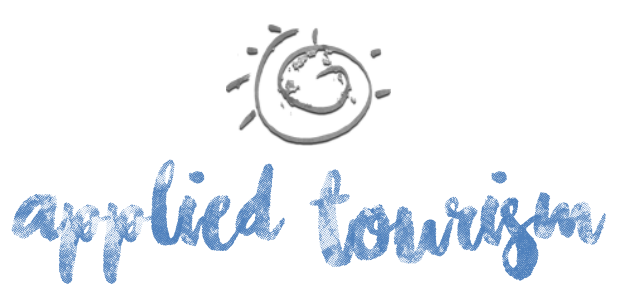

Volume 2, número 1,2017, p. 68-94

motivar os consumidores através da interpretação das necessidades agregando valor ao produto, através de ofertas diferenciadas ao mercado, adaptando a oferta aos diferentes segmentos de mercado.

No entanto, deve-se considerar que, na venda de produtos turísticos, são necessárias mais do que apenas estratégias de marketing. A demanda na área de serviços sofre influência das características da empresa e de seu mercado, como o tamanho desse mercado, as ações de seus competidores, além da estratégia adotada e condições do mercado local quanto à infraestrutura e desenvolvimento econômico (Rubalcaba \& Merino, 2005).

Kotler \& Armstrong (2007) afirmam que no nível atual de competitividade não basta utilizar o bom senso ou a experiência para definir as estratégias empresariais. As empresas precisam se organizar, precisam estar orientadas ao marketing e procurar "aprender e entender as necessidades, os desejos e as demandas de seus clientes".

Ao originar em uma cultura diferente, a oferta deve levar em conta a cultura local. Na economia global muitas empresas recorrem aos mercados de negócios alternativos, como acontece no mercado de cruzeiros no Brasil, cuja oferta é baseada em empresas multinacionais. Segundo Powers e Loyka (2010) a adaptação do produto ao mercado local é um fator que deve ser considerado nas estratégias mercadológicas das empresas.

Neste contexto, Ramoa (2014) e Ramoa \& Flores (2015b), afirmam que as companhias de navegação que embarcam passageiros no Brasil, disponibilizam ao mercado brasileiro navios de cruzeiro padrão internacional, três e quatro estrelas, medidos de acordo com sistema de classificação do Guia Berlitz (Ward, 2013), sendo que, segundo os autores, essa não é a razão por trás da tendência de queda na demanda de cruzeiros no Brasil. 


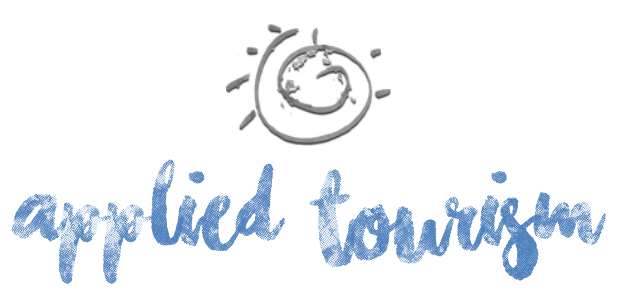

Volume 2, número 1,2017, p. 68-94

equações, obtidas através da análise de regressão estatística, utilizadas para extrapolação dos resultados e consequente previsão da demanda futura (Levine, Berenson, \& Stephan, 2000).

Nos estudos realizados sobre o comportamento das variáveis turísticas, as relações causaefeito entre as variáveis são refletidas por meio de uma estrutura de equações, em função disso, foram determinadas as equações de regressão, que, segundo Sancho-Perez (2006, p. 142), são utilizadas para se "efetuar predições do comportamento futuro", ou seja, para que possa ser calculada a tendência a partir dos gráficos ou diagramas de dispersão.

Desta forma, os cálculos estatísticos de regressão foram utilizados para a análise dos dados existentes, procurando sempre um comportamento tendencial das variáveis envolvidas, de forma a poder criar a equação matemática que melhor explique este comportamento. Através desta equação tornou-se possível a extrapolação dos dados, permitindo a realização de previsões futuras (Barbosa \& Milone, 2004).

Este método de análise de dados considera que o comportamento do sistema abrangido se manterá inerte, seguindo uma tendência. Qualquer alteração do sistema que modifique as variáveis envolvidas e que não esteja prevista no modelo de regressão acarretará em modificações desta tendência (Barbosa \& Milone, 2004).

Ao se encontrar relações tendenciais com $\mathrm{R}^{2}$ considerado muito bom, ou seja, próximo de 1 e curvas de regressão adequadas à dispersão dos dados, é necessário um bom grau de análise do pesquisador para verificar o enquadramento da situação calculada com a realidade encontrada.

De acordo com Hair, Black, Babin, Anderson \& Latham (2007, p. 159), o conhecimento do pesquisador sobre o contexto da pesquisa é um dos critérios mais importantes na análise da regressão. "Sem esse conhecimento, os resultados da regressão podem ter elevada precisão preditiva sem qualquer relevância gerencial teórica". O pesquisador deve, 


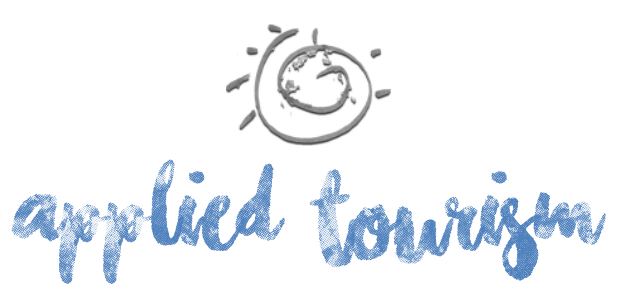

Volume 2, número 1,2017, p. 68-94

um forte crescimento da demanda até a temporada 2010/2011, estabilizando-se na temporada 2011/2012, quando ocorreu o seu pico com o embarque de 805.189 cruzeiristas, para em seguida iniciar um período de queda com o embarque de 732.163 passageiros em 2012/2013, alcançando 597.011 previsto para 2015-2016 (CLIA-ABREMAR, 2016b) confirmando a tendência de queda apontada por Ramoa (2014) and Ramoa \& Flores (2015a).

É possível verificar na Figura 1, que, se toda a série for analisada de uma só vez na procura de uma tendência dos dados existentes, esta irá resultar em uma curva com concavidade para baixo, com a demanda tendendo à queda, sugerindo que se trata de uma curva do tipo polinomial.

Em alguns casos, quando se deseja obter um ajuste adequado da curva ao conjunto de dados, Milone (2004) considera conveniente buscar alternativas em curvas com equações com maior grau. Nesta análise, foram procuradas as curvas com o melhor $\mathrm{R}^{2}$, obtendo-se as equações polinomiais de segunda e terceira ordem, conforme demonstrada na Figura 2 a seguir.

Figura 2 - Brasil: Análise de regressão estatística. Linhas de tendência polinomial da demanda de cruzeiristas

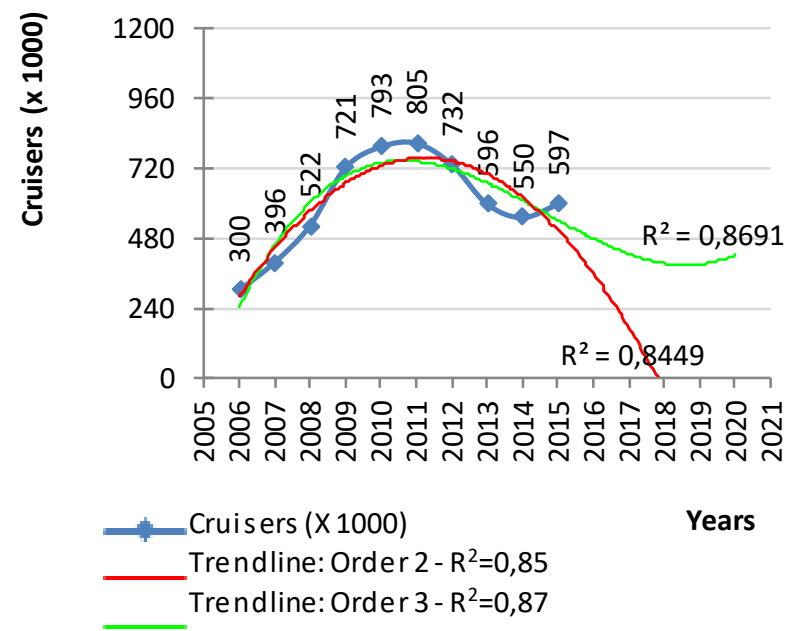

Fonte: do autor adaptado de CLIA-ABREMAR CLIAABREMAR BRASIL (2015; 2016b) 


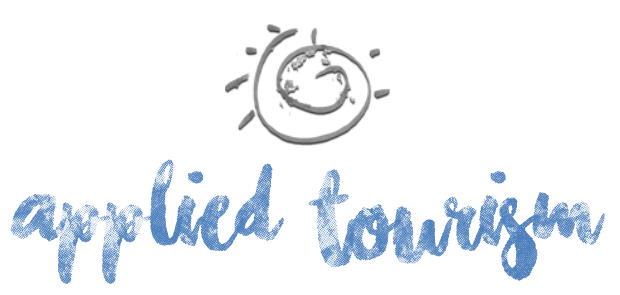

Volume 2, número 1, 2017, p. 68-94

Foram analisados outros tipos de linhas de regressão, como exponencial, por exemplo, que apesar de apresentarem tendência de crescimento, não possuem o coeficiente de correlação $\mathrm{R}^{2}$ satisfatório, estando próximos a 0,3 , ou 30\%, indicando que aproximadamente 70\% dos dados não são explicados pelas linhas, portanto, não permitindo desta forma condições para confiabilidade de seu uso para predições futuras.

Em relação à equação do segundo grau, apesar de apresentar um $\mathrm{R}^{2}$ satisfatório de 0,85, menor que a de terceiro grau, ela apresenta uma tendência de queda menos pronunciada e que se encaixa melhor com os dados. No entanto, deve notar-se que a diminuição da procura nos últimos quatro anos da série histórica foi responsável pela inversão da tendência para baixo, a qual que conduz a uma queda estimada tão rápida quanto ao crescimento inicial do setor. Ao realizar uma análise mais crítica, deve notar-se que o período de quatro temporadas é muito curto para determinar uma tendência de longo prazo, além de que as primeiras oito temporadas apresentaram crescimento estável da demanda (CLIA ABREMAR BRASIL, 2015; 2016b). Para calcular a tendência da demanda com maior precisão seria necessária uma série histórica mais longa, dessa forma, o resultado dessa análise de um curto período sobre as perspectivas futuras, é enganosa.

Uma questão é oportuna neste momento, trata-se de se saber como seria a tendência, caso não houvesse a queda da demanda nas últimas temporadas. Será então apresentada uma simulação com um novo cálculo, considerando-se a série de dados até a temporada 2011/2012, excluindo-se assim o período posterior.

O resultado desta análise permitirá realizar um comparativo entre os dados calculados com os dados reais apresentados nas temporadas 2012/2013 e 2015/2016, possibilitando a visualização da perda do número de cruzeiristas no período. Esta simulação também permitirá estimar o número de cruzeiristas que seria alcançado até a temporada 2018/2019, caso a tendência de crescimento tivesse se mantido. 


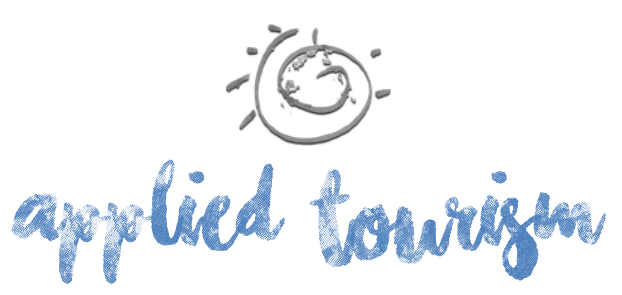

Volume 2, número 1,2017, p. 68-94

Desta forma elaborou-se o diagrama de dispersão a seguir (Figura 3), onde apresenta-se a linha de tendência, seu respectivo $\mathrm{R}^{2}$ e sua equação matemática com base nos dados do período de crescimento da demanda entre 2004/2005 e 2011/2012:

Figura 3 - Brasil: Análise de regressão estatística. Linha de tendência linear da demanda de cruzeiristas

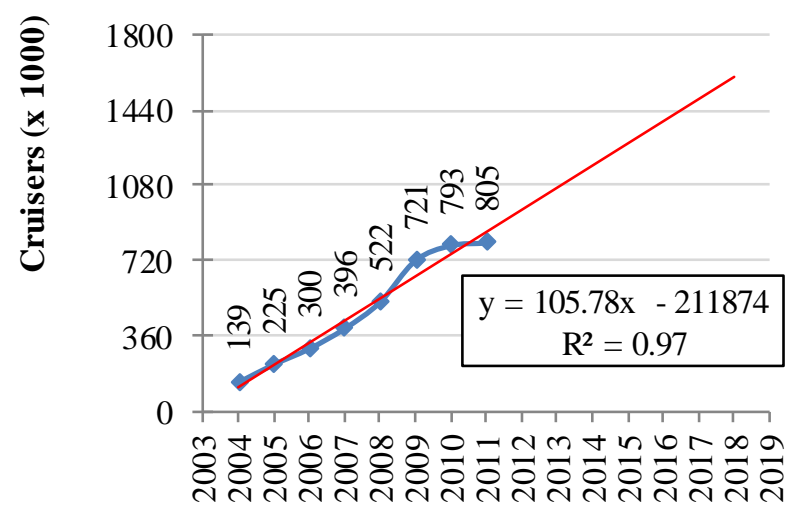

Years

$\leadsto$ Brazil (x 1000) $\longrightarrow$ Trendline

Fonte: do autor adaptado de CLIA-ABREMAR (2011, 2013b, 2013c)

A linha de tendência exibida no diagrama de dispersão (Figura 3) projeta uma perspectiva de otimismo para o futuro. Esta linha é do tipo linear, cujo coeficiente de correlação R² é 0,97, indicando que 97\% dos dados possuem correlação entre as variáveis e por consequência há validade dos resultados da relação estimada.

O erro padrão da estimativa $\left(S_{\mathrm{yx}}\right)$ obtido a partir da equação linear, foi calculado em 40.488 cruzeiristas. Sendo assim, a partir da equação da reta, foram calculadas as novas projeções da demanda para as temporadas de 2012/2013 a 2018/2019 (Tabela 1): 


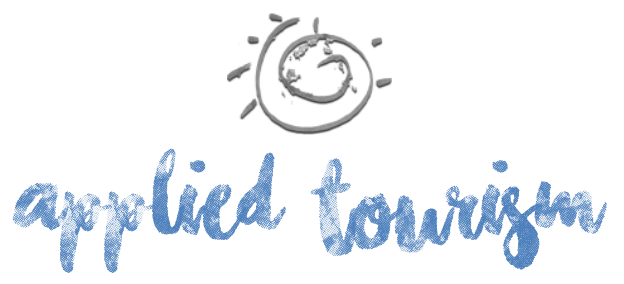

Volume 2, número 1,2017, p. 68-94

nos Estados Unidos e espalhou-se por todo o mundo. A segunda conhecida como "primavera árabe", foi um acontecimento político ocorrido no Norte da África, no início de 2011, causado pelas insurreições ocorridas no Egito, Tunísia e pela guerra civil na Líbia (Joffe, 2011) a qual gerou uma crise na região do euro, afetando o comportamento do mercado europeu, devido ao cancelamento das escalas nos portos da Tunísia e Egito, destinos chave deste mercado.

O evento no norte da África também inibiu potenciais cruzeiristas a fazerem um cruzeiro devido à movimentação militar que ocorreu na região neste período de crise. Outro evento que também afetou o mercado europeu foi o acidente do navio Costa Concordia, que aconteceu em janeiro de 2012. Todos estes acontecimentos afetaram de alguma maneira o turismo marítimo, em alguns países mais do que em outros (CLIA-EUROPA, 2012b, 2013a). A seguir são apresentados os gráficos de regressão dos principais países do ranking mundial de cruzeiros marítimos. Para se traçar as linhas de tendência destes países foram considerados não só a obtenção de um melhor coeficiente de determinação $R^{2}$, mas também foi feita a análise crítica da linha, de sua equação e de sua direção. 


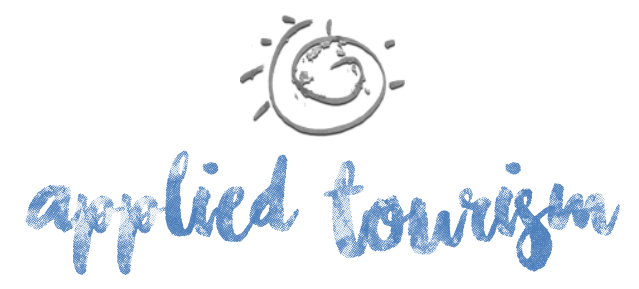

Volume 2, número 1,2017, p. 68-94
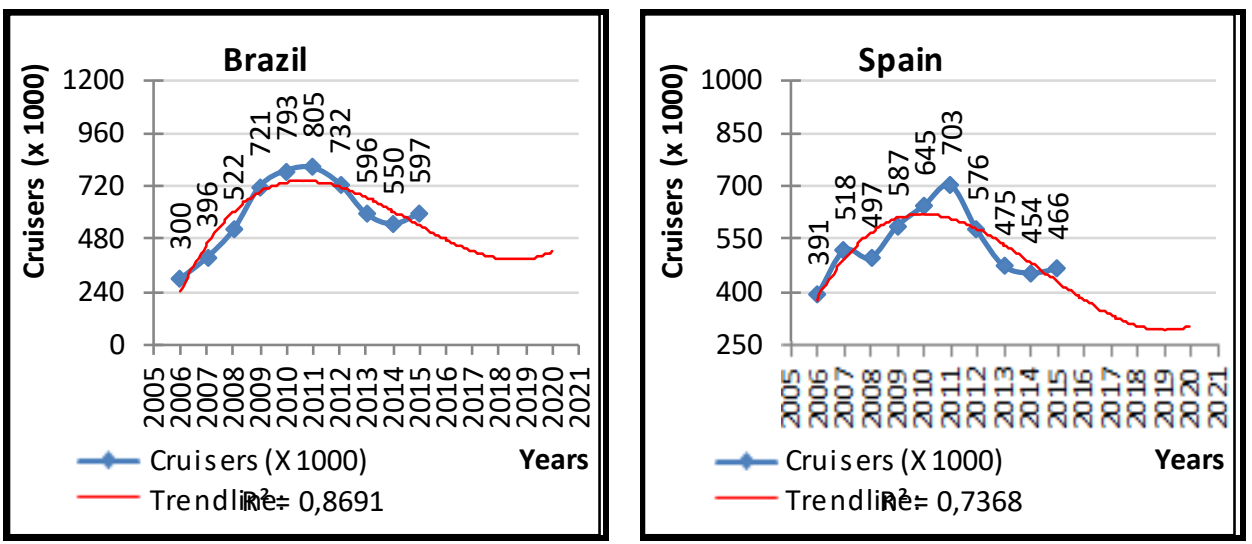

Source: Adapted from CLIA (2009; 2010; 2011; 2013a; 2016); CLIA ABREMAR BRASIL (2015; 2016b); CLIA Australia (2015); CLIA Europe (CLIA Europe, 2012b; 2013c; 2015a; 2015b; 2015c); (Cruise Market Watch, 2015)

Ao contrário do que ocorreu, primeiro com os Estados Unidos, ao final de 2008 e depois com a Europa, que sofreram com a crise econômica internacional, países como Austrália e Brasil ficaram imunes a esta crise (CLIA-Europa, 2013b). A Austrália apresentou uma série histórica com crescimento contínuo indicando que não houve qualquer fator que influenciasse negativamente o comportamento de sua demanda. Já o Brasil, apesar de não ter sido afetado, nem com crises internas, conforme informado anteriormente, nem externas, tem demonstrado resultados negativos da demanda ano a ano, desde a temporada 2012/2013.

O Canadá, por sua vez, além da crise econômica internacional de 2008, apresenta uma razão particular para a modificação do comportamento de sua demanda. Identificou-se que a queda também foi motivada pela competição que existe entre os portos canadenses e americanos. Os cruzeiristas com destino ao Alaska passaram a embarcar em Seattle, Estados Unidos, ao invés de Vancouver, o maior porto do Canadá, responsável por 33\% do trânsito de passageiros no país, o que refletiu em uma queda de 32\% no número de embarques neste porto canadense no período de 2007 a 2012, passando de 494.864 para 375.255 passageiros embarcados (CLIA-North West \& Canada, 2013a).

Com o embarque de passageiros ocorrendo em Seattle, o porto de Victoria, no Canadá, passou a ser o principal porto de escala para os navios com destino ao Alaska. Com estas 


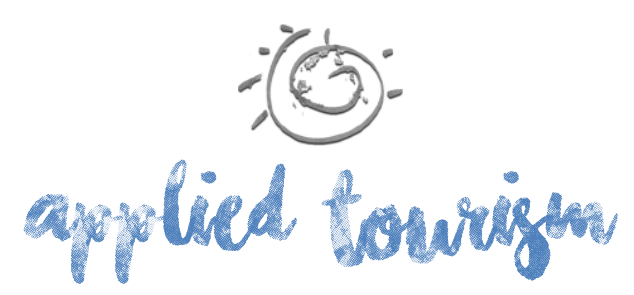

Volume 2, número 1, 2017, p. 68-94

alterações do comportamento da demanda, a CLIA-NORTH WEST \& CANADA afirma que apesar de haver uma tendência ascendente no número de passageiros nos últimos anos, a demanda tem flutuado ano a ano como consequência de dois fatores, o primeiro relativo à mudança de itinerário realizado pelas companhias marítimas e o segundo devido aos impactos das crises econômicas no país (CLIA-North West \& Canada, 2013b).

Enquanto o Canadá apresenta tendência de crescimento da demanda, após o pico da oferta de 20 navios de cruzeiro, ocorrida no Brasil em 2010/2011, iniciou-se uma queda nas temporadas seguintes, quando foram oferecidos 17 embarcações em 2011/2012, 15 em 2012/2013 e 11 em 2013/2014. Como consequência desta queda, houve a diminuição da oferta de leitos em 15\%, na temporada 2013/2014 em relação à 2012/2013, que teve 762.000 leitos disponíveis (CLIA ABREMAR BRASIL, 2011; 2016b). A redução da oferta de leitos, pode ter sido um dos motivos da queda da demanda, no entanto, nota-se que o início desta queda ocorreu em 2011/2012, portanto, antes da diminuição da demanda, que só aconteceu em 2012/2013.

Este comportamento do mercado brasileiro leva a diversos questionamentos sobre os motivos que tem feito a oferta e a demanda por passageiros terem reduzido tão rapidamente após terem experimentado períodos tão prósperos, levando-se a considerar outros motivos para este desempenho, comoa possibilidade do ciclo de vida deste produto turístico estar entrando na fase de declínio no Brasil, ou mesmo se as companhias passaram a optar por outros mercados mais atraentes, ou ainda devido a problemas com a infraestrutura e os elevados custos operacionais no Brasil, apontados pela CLIA ABREMAR BRASIL (2010; 2015) e confirmados por Ramoa (2014).

A economia espanhola vem sofrendo mais do que a maioria dos países da Europa, devido às crises de 2008 e de 2012, embora o mercado de cruzeiros já venha demonstrando sinais de recuperação nos últimos anos, retomando o crescimento com taxas superiores ao restante do setor turístico do país (CLIA-Europa, 2013a). 


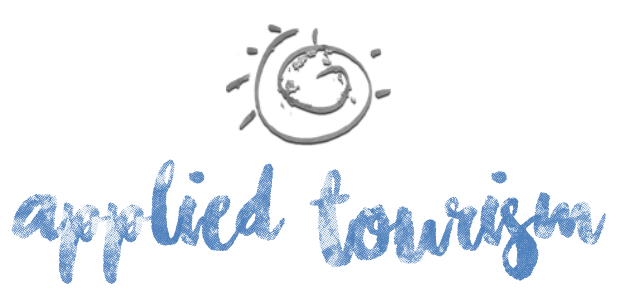

Volume 2, número 1,2017, p. 68-94

Conclui-se que as crises políticas e econômicas, além de desastres naturais e outras variáveis do mercado, podem influenciar o comportamento de um mercado durante um certo período de tempo, ou permanentemente, dependendo da situação. Isso é o que tem ocorrido em vários países que tenham passado por algum tipo de crise, mas, no entanto, retomaram o crescimento, mostrando que, quando há uma limitação na oferta ou na demanda - seja de natureza económica, política, social ou estrutural - quando essa limitação é eliminada, o mercado tende a voltar a uma trajetória de crescimento. Portanto, é importante que os destinos turísticos estejam prontos para responder a crises potenciais, que possam afetar o seu desenvolvimento. Além disso, com o apoio das autoridades públicas, um plano estratégico deve ser elaborado tendo em conta a possível ocorrência de situações extremas. Afinal, apesar dos efeitos negativos das crises, uma boa gestão de crises pode reverter a situação e trazer novas oportunidades.

\section{CONSIDERAÇÕES FINAIS}

Ao se comparar os dados da demanda por cruzeiros marítimos do mercado brasileiro com o mercado internacional, analisando-se suas curvas de crescimento e constatando que a tendência futura calculada também é de crescimento em todos os mercados analisados nos próximos anos, pode-se dizer que a perspectiva do mercado brasileiro de cruzeiros marítimos para os próximos anos é de manter taxas decrescentes da demanda, a menos que os fatores que estejam influenciando este comportamento do mercado sejam identificados e alguma ação seja feita para reverter esta tendência.

Cabe salientar que diferente do que acontece nos mercados da América do Norte e Europa, que possuem uma série histórica de dados maior e um mercado consolidado, a quantidade de dados disponíveis para o mercado brasileiro ainda não é suficiente para se ter uma precisão dos resultados obtidos. No entanto, independentemente da quantidade de dados ou estimativas mais precisas, a queda contínua da demanda no Brasil desde a temporada 2012-2013, com uma queda de 26\% no número de passageiros, até 2015-2016, é suficiente, por si só, para chamar a atenção do setor. 


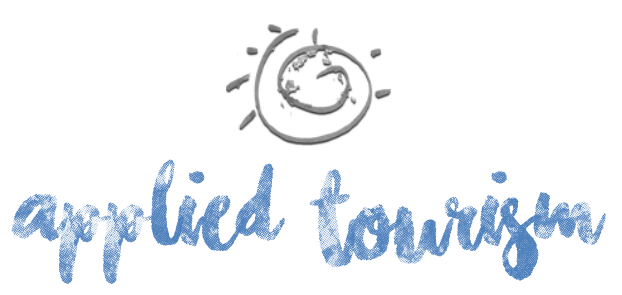

Volume 2, número 1,2017, p. 68-94

Assim, comparando o Brasil com as curvas dos países com demanda semelhante, em particular, a Austrália e o Canadá, os números são alarmantes, o que incentiva a realização de novas pesquisas sobre a demanda de cruzeiro, de modo a aprofundar a compreensão do processo de tomada de decisão dos consumidores. É também essencial avaliar as variáveis do lado da oferta, a respeito das decisões estratégicas das empresas, como o número de navios de cruzeiro disponíveis ou a duração das temporadas.

Esta pesquisa apresenta uma previsão preocupante para o mercado de cruzeiros no Brasil nos próximos anos. Apesar de ter vivido um período de prosperidade e de ter alcançado uma posição de destaque no ranking internacional do turismo de cruzeiros, o Brasil está enfrentando agora uma tendência de queda, o que pode se tornar uma realidade permanente.

\section{REFERÊNCIAS}

Almeida, P., Miranda, F., \& Elias-Almeida, A. (2012). Aplicação da análise importância-valor aos componentes da imagem de um destino turístico. Tourism \& management studies, 8, pp. 65-77. Faro.

Amadeus. (2009). Future traveller tribes 2020: relatório para a indústria de viagens. Acesso em 24 de Agosto de 2016, available in Henley Centre HeadlightVision: http://www.amadeus.com/br/documents/aco/br/pt/travellertribes_por.brfinal.pdf

BACEN. (2016). Banco Central do Brasil. Acesso em 24 de Agosto de 2016, available in Indicadores econômicos consolidados. CapítuloVI -Economia internacional. Indicadores econômicos. Países selecionados. PIB nominal. Brasília: http://www.bcb.gov.br/?INDECO

Barbosa, D. L., \& Milone, G. (2004). Estatística aplicada ao turismo e botelaria. São Paulo: Pioneira Thomson Learning.

CLIA. (2009). Cruise Line International Association. Fonte: 2009 CLIA Cruise Market Overview: Statistical Cruise Industry Data Through 2008.

CLIA. (2010). Cruise Line International Association. Acesso em 1 de Junho de 2016, available in The Overview. 2010 CLIA Cruise Market Overview. Stastistical cruise industry data through 


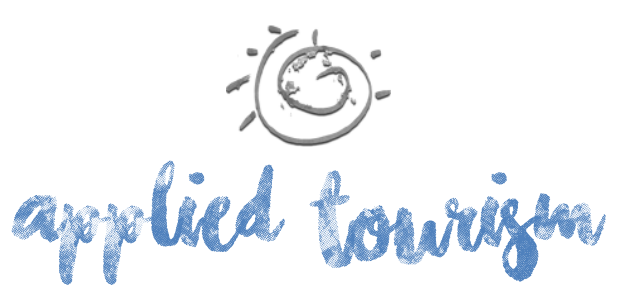

Volume 2, número 1, 2017, p. 68-94

2009:

http://muskingum.edu/ bking/2011nyno/1_2010_clia_cruise_market_overview.pdf

CLIA. (2011).Cruise Line International Association. Acesso em 1 de Junho de 2016, available in The Overview. 2011 CLIA Cruise Market Overview. Stastistical cruise industry data through 2010 : http://www.cruising.org/docs/default-source/market-research/clia-cruise-marketoverview-report-(pdf).pdf?sfvrsn $=0$

CLIA. (2013a). Cruise Line International Association. Acesso em 1 de Junho de 2016, available in 2013 North America cruise industry update: http://www.cruising.org/docs/defaultsource/market-research/2013-cruise-industry-update.pdf?sfvrsn =0

CLIA. (2013b). Cruise Line International Association. Acesso em 24 de Agosto de 2016, available in CLIA: $2013 \quad$ Cruise Industry: http://www.cruising.org/sites/default/files/pressroom/January30Deck_FINAL.pdf

CLIA. (2014). Cruise Line Industry Association. Acesso em 6 de Junho de 2016, available in The contribution of the International Cruise Industry to the U.S. economy in 2014: http://www.cruising.org/docs/default-source/market-

research/clia_2014eis_us.pdf?sfursn $=0$

CLIA. (2016). Cruise Line International Association. Acesso em 4 de Junho de 2016, available in 2016 Cruise industry outlook: http://www.cruising.org/docs/defaultsource/research/2016_clia_sotci.pdf?sfvrsn $=0$

CLIA ABREMAR BRASIL. (2006). Associação Brasileira de Representantes de Empresas Marítimas. Acesso em 24 de Agosto de 2016, available in Caracterização da demanda e dimensionamento de impactos econômicos nas viagens de cruzeiros marítimos no Brasil. São Paulo: http://migre.me/ePe7l

CLIAABREMAR BRASIL. (2010). Associação Brasileira de Representantes de Empresas Marítimas. Acesso em 10 de abril de 2016, available in Infraestrutura portuária no Brasil: http://www.globalgarbage.org/turmapontocom/downloads/ABREMAR\%20Estudos\%20do s\%20Portos\%20FINAL_2011.pdf

CLIAABREMAR BRASIL. (2011). Associação Brasileira de Representantes de Empresas Marítimas. Acesso em 17 de maio de 2016, available in Cruzeiros marítimos: estudo de perfil e impactos econômicos no Brasil. São Paulo: http://www.abremar.com.br/down/fgv2011.pdf

CLIAABREMAR BRASIL. (2015). Associação Brasileira de Representantes de Empresas Marítimas. Acesso em 5 de Junho de 2016, available in FGV Projetos. Maritime Cruises: Study on Profile and Economic Impacts in Brazil. Season 2014-2015: http://www.abremar.com.br/down/Cruzeiros_2015_Final_WEB_Ingles.pdf

CLIAABREMAR BRASIL. (2016a). Associação Brasileira de Representantes de Empresas Marítimas. Acesso em 5 de Junho de 2016, available in Associados: http://www.abremar.com.br/cliaabremar-brasil/ 


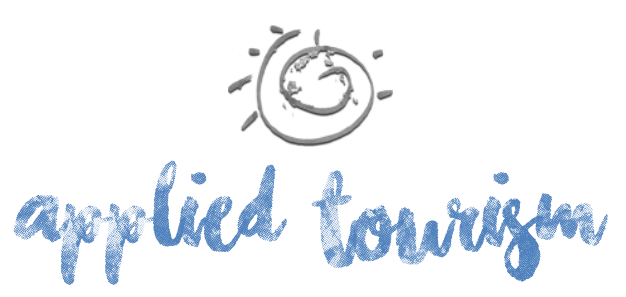

Volume 2, número 1, 2017, p. 68-94

CLIA ABREMAR BRASIL. (2016b). Associação Brasileira de Representantes de Empresas Marítimas. Acesso em 3 de Maio de 2016, available in Temporadas 2010/2011 -2011/2012 - 2012/2013 - 2013-2014 - 2014-2015 - 2015-2016. São Paulo: http://www.abremar.com.br/temporadas

CLIA ABREMAR BRASIL. (2016c). Associação Brasileira de Representantes de Empresas Marítimas. Fonte: CLIA ABREMAR DIVULGA DADOS DA TEMPORADA 2016/2017 DE CRUZEIROS MARÍTIMOS NO PAÍS: http://abremar.hospedagemtemporaria.com.br/clia-abremardivulga-dados-da-temporada-20162017-de-cruzeiros-maritimos-no-pais/

CLIA Australia. (2015). Acesso em 5 de Junho de 2016, available in Cuise industry source market report: Ocean Cruise Passengers, Australia 2015: http://www.cruising.org/docs/defaultsource/research/australia-market-report-2015.pdf?sfvrsn $=0$

CLIA Europe. (2012a). European Cruise Council. Acesso em 24 de Agosto de 2016, available in ECC 2011/2012 Report: making a real social and economic contribution to Europe's economy. London:

http://www.europeancruisecouncil.com/content/ECC\%20Report\%202011\%202012.pdf

CLIA Europe. (2012b). European Cruise Council. Acesso em 24 de Agosto de 2016, available in ECC 2010/2011 Report: Grow, develop, innovate, build, protect, health, people, communities, responsible, safe, environment, enjoyment, holidays: http://www.ashcroftandassociates.com/images/ECC-LR.pdf

CLIA Europe. (2013a). European Cruise Council. Acesso em 24 de Agosto de 2016, available in ECC becomes CLIA: Europe in new association model to promote one industry, one voice. London: http://www.europeancruisecouncil.com/NewsDetails.aspx?uNewsID=166

CLIA Europe. (2013b). European Cruise Council. Acesso em 24 de Agosto de 2016, available in ECC 2012/2013 Report. London: http://www.europeancruisecouncil.com/content/ECC\%20Report\%202012-13.pdf

CLIA Europe. (2013c). European Cruise Council. Acesso em 24 de Agosto de 2016, available in The cruise industry: Contribution of Cruise Tourism to theEconomies of Europe 2013 Edition. London: http://www.cruise-norway.no/viewfile.aspx?id=3824

CLIA Europe. (2015a). European Cruise Council. Acesso em 5 de Junho de 2016, available in The Cruise industry: Contribution of Cruise Tourism to the Economies of Europe 2015 Edition: http://www.cruising.org/docs/default-source/market-research/2015-europe-economicimpact-study.pdf?sfursn $=0$

CLIA Europe. (2015b). European Cruise Council. Acesso em 1 de Junho de 2016, available in Statystcs and Markets 2015: http://www.cliadeutschland.de/pdf/07160311CLIAStudiePassagierzahlenEuropa2015.pdf

CLIA Europe. (2015c). European Cruise Council. Acesso em 16 de Junho de 2016, available in The Cruise Industry: Contribution of Cruise Tourism to the Economies of Europe 2014 Edition: http:/www.cliaeurope.eu/images/downloads/reports/CLA_2014.pdf 


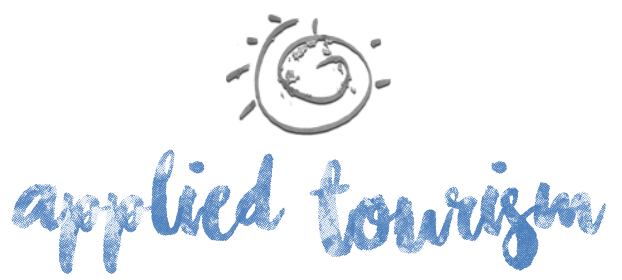

Volume 2, número 1,2017, p. 68-94

Tomelin, C. A., Ruschmann, D. V., \& Argenta, D. (2013). Segmentação de mercado: intercâmbio internacional para pessoas com mais de 50 anos. Em C. Ramos, M. Correia, F. Serra, J. Santos, \& P. Águas, Competitividade, marketing e tecnologias de informação e comunicaçãono turismo (pp.123-134). Faro: TMS Conference Series .

Vogel, M., \& Oschmann, C. (2012). The demand for ocean cruises - The three perspectives. Em M. Vogel, A. Papathanassis, \& B. Wolber, The business and management of ocean cruises (pp.3-18). Wallingford, UK: Cabi.

Ward, D. (2013). Complete guide to cruising \& cruise ships. London: Berlitz Publishing.

WTO. (2010). Cruise Tourism: Current Situation and Trends. World Tourism Organization, Madri. 